\title{
ATUAÇÃO DOS PROFISSIONAIS DA ATENÇÃO PRIMÁRIA EM SAÚDE EM RELAÇÃO AO MOVIMENTO ÁNTIVACINAÇÃO
}

\author{
Júlia Simeoni do Nascimento', Giovanna Sabedotti Tyszka ², Caroline Rodrigues de \\ Almeida ${ }^{3}$, Célia Maria Gomes Labegalini4
}

\begin{abstract}
1'Acadêmica do curso de Medicina, Centro Universitário de Maringá - UNICESUMAR, Bolsista PIC-UniCesumar. julia.s.n@hotmail.com ${ }^{2}$ Acadêmica do curso de Medicina, Universitário de Maringá - UNICESUMAR, Bolsista PIC-UniCesumar. gikastyszka@gmail.com ${ }^{3}$ Co-rientadora, Mestre, Centro de Ciências e Biológicas e da Saúde, UNICESUMAR. caroline.almeida@unicesumar.edu.br ${ }^{4}$ Orientadora, Mestre, Centro de Ciências e Biológicas e da Saúde, UNICESUMAR. celia.labegalini@unicesumar.edu.br
\end{abstract}

\section{RESUMO}

O Movimento Antivacina ganhou espaço nos últimos anos, impactando na cobertura vacinal e na recorrência de doenças erradicadas, tornando-se uma preocupação para os profissionais da Atenção Primária à Saúde (APS). Sendo assim, esse estudo tem como objetivo entender como os profissionais da APS se organizam e planejam estratégias em relação ao Movimento Antivacina. O estudo seguirá todos os preceitos éticos da resolução 466/2012 e terá como participantes os profissionais de saúde que atuam na gestão e administração de imunobiológicos vinculados a 34 Unidade Básicas de Saúde (UBS) do município de Maringá-PR. Será realizada entrevista individual utilizando um roteiro semi-estruturado elaborado pelas pesquisadoras, composto por questões de caracterização e sobre os conhecimentos acerca da vacinação e do Movimento Antivacina. Os dados serão coletados e analisados por análise temática de conteúdo organizado em três fases: pré-análise; exploração do material e tratamento dos resultados; inferência e interpretação. Espera-se, com essa pesquisa, compreender, na perspectiva dos profissionais, tal movimento e elencar as estratégias que os profissionais da APS estão adotando em relação ao Movimento Antivacina, esses dados poderão subsidiar novas práticas em saúde pública e fortalecer as ações pró-vacinação.

PALAVRAS-CHAVE: Imunização; Projetos de Saúde; Unidade Básica de Saúde; Recusa da Vacinação.

\section{INTRODUÇÃO}

A primeira política pública no Brasil referente à imunização ocorreu em 1811, pela família real portuguesa, a qual criou a Junta Vacínica da Corte que foi responsável em expandir a vacinação antivariólica na cidade do Rio de Janeiro com objetivo de evitar a transmissão da doença. No entanto, somente por meio da Constituição de 1824 a imunização foi inserida em outras regiões do país. Essa constituição previu a obrigatoriedade da vacinação de todas as crianças após os três meses do nascimento, e o pagamento de multa caso os pais não cumprissem o que se previa. Todavia, grande parte da população continuava sem a imunização (SCHATZMAYR, 2012).

Em 1846 ocorreu uma intensificação de investimentos na produção de vacinas utilizadas no país pelo Instituto Vacínico do Império. Contudo, evidenciou-se que a vacinação, como estratégia isolada, não era efetiva. Foi então, repensado as questões ambientais e a relevância do saneamento básico no controle das epidemias, culminada a criação da Inspetoria Geral de Higiene, em 1886, que realizou diversas ações especialmente no Rio de Janeiro (SCHATZMAYR, 2012; COUTO, BARBIERI, 2015).

Em 1846 ocorreu uma intensificação de investimentos na produção de vacinas utilizadas no país pelo Instituto Vacínico do Império. Contudo, evidenciou-se que a vacinação, como estratégia isolada, não era efetiva. Foi então, repensado as questões ambientas e a relevância do saneamento básico no controle das epidemias, culminando na criação da Inspetoria Geral de Higiene, em 1886, que realizou diversas ações especialmente no Rio de Janeiro (SCHATZMAYR, 2012; COUTO, BARBIERI, 2015).

Diante deste contexto, o governo decretou a Lei da Vacina Obrigatória, em 1904, organizada pelo médico Oswaldo Cruz com apoio do exército. Esta Lei imunizou a população de forma compulsória e violenta, o que resultou na erradicação da varíola no 
Rio de Janeiro e desencadeou o movimento conhecido como "Revolta da Vacina" (SCHATZMAYR, 2012).

Dessa forma, as campanhas de imunização levou a criação do Programa Nacional de Imunização (PNI), em 1973, voltado a estratégias integradas para o controle de doenças por meio da vacinação, com abordagem a população de forma consentida e orientada, mas ainda obrigatória. Definiu-se também o calendário vacinal (BRASIL, 2003), realizado na Atenção Primária em Saúde (APS), e sua implantação alterou o perfil de morbimortalidade no país.

Mesmo com tamanha importância na erradicação de doenças, as vacinas são alvos frequentes de críticas e dúvidas sobre sua eficiência. Essas se dão, usualmente, pela desinformação ou popularização das notícias falsas, que frequentemente distorcem e divulgam dados infundados contribuindo para o fortalecimento de um movimento intitulado Antivacina. Este movimento ganhou espaço no Brasil e já foi responsável por reduzir a cobertura vacinal, o que pode levar a surtos de doenças, inclusive as já erradicadas. Por isso, os profissionais de saúde, especialmente os da APS, precisam conhecer tal movimento e atuar incentivando a vacinação. (VASCONCELLOS-SILVA, P.R.; CASTIEL, L.D.; GRIEP, 2015; APS et al., 2018). Assim, é fundamental entender como os profissionas da APS se organizam e planejam estratégias em relação ao Movimento Antivacina.

Dessa maneira, esse estudo debruça-se na seguinte questão de pesquisa: Como os profissionais da APS se organizam em relação ao Movimento Antivacina? E objetiva-se analisar as estratégias adotadas pelos profissionais de saúde em relação ao Movimento Anti-vacinação.

\section{MATERIAIS E MÉTODOS}

Pesquisa qualitativa, do tipo exploratória e descritiva. A natureza qualitativa em virtude de focar-se às situações complexas e estritamente particulares (GIL, 2017) como as perspectivas e ações dos profissionais frente ao Movimento Antivacina. Enquanto pesquisa qualitativa, buscou-se a compreensão intensa do fenômeno de interesse (APPOLINÁRIO, 2009), a fim de obter interpretação ampla dos dados, mediante a ligação harmônica com os conhecimentos disponíveis (GIL, 2017).

Para tanto, o delineamento metodológico exploratória-descritivo, almeja descrever minuciosamente o fenômeno antivacinação e as ações dos profissionais para estimular a vacinação, dando precedência ao caráter representativo sistemático (MARCONI; LAKATOS, 2017).

Os participantes do estudo serão os profissionais da APS e o coordenador de imunobiológicos da Secretaria Municipal de Saúde (SMS) de Maringá-PR. Critérios de inclusão: atuar em sala de vacina ou na gestão de imunobiológicos. Critério de exclusão: atuar a menos de um ano na área. O local de pesquisa será a rede de APS do município de Maringá-PR, a mesma possui 34 Unidades Básicas de Saúde (UBS) e mais uma sala de vacinação localizada dentro da SMS.

Os dados serão coletados utilizando roteiro semi-estruturado elaborado pelas pesquisadoras, composto de questões de caracterização dos participantes e sobre as percepções sobreo Movimento Antivacina e estratégias para melhorar a adesão à vacinação. Os profissionais serão abordados no local de trabalho, em dia e horário prédefinidos. A entrevista será gravada em áudio e realizada em sala reservada.

Os dados serão transcritos na íntegra e analisados por análise temática de conteúdo (BARDIN, 2011), a o qual as organiza em três fases: 1) pré-análise, 2) exploração do material e 3) tratamento dos resultados, inferência e interpretação. 
A pré-análise é a fase em que se organiza o material a ser analisado com o objetivo de torná-lo operacional, sistematizando as ideias iniciais (BARDIN, 2011).

A exploração do material constitui a segunda fase, que consiste na exploração do material com a definição de categorias e a identificação das unidades de registro e das unidades de contexto nos documentos. Esta é a fase da descrição analítica, a qual diz respeito ao corpus (qualquer material textual coletado) submetido a um estudo aprofundado, orientado pelas hipóteses e referenciais teóricos. Dessa forma, a codificação, a classificação e a categorização são básicas nesta fase (BARDIN, 2011).

A terceira fase diz respeito ao tratamento dos resultados, inferência e interpretação; é o momento da intuição, da análise reflexiva e crítica (BARDIN, 2011).

Essa pesquisa seguirá todas as premissas da Resolução $n^{\circ}$ 466/2012. Assim, somente será iniciada após parecer favorável do Comitê de Ética em Pesquisa do Centro Universitário de Maringá (UNICESUMAR) e da autorização da Assessoria de Formação e Capacitação Permanente dos Trabalhadores de Saúde (CECAPS), órgão competente da Secretaria Municipal de Saúde de Maringá-PR, mediante assinatura de autorização para a realização da pesquisa. Os participantes serão incluídos no estudo após assinatura do Termo de Consentimento Livre e Esclarecidos (TCLE).

\section{RESULTADOS ESPERADOS}

Espera-se, com esse estudo, elencar as estratégias que os profissionais da APS estão desenvolvendo e adotando em relação ao movimento antivacina, bem como conhecer as percepções desses profissionais ao movimento. Os dados poderão subsidiar novas práticas em saúde pública e fortalecer as ações pró-vacinação. Além de compreender, na perspectiva dos profissionais, tal movimento e seus impactos na saúde da população.

\section{REFERÊNCIAS}

APPOLINÁRIO, F. Metodologia da Ciência: Filosofia e Prática da Pesquisa. São Paulo (SP): Cengage Learnig, 2009.

APS, L.R. M.M.; PIANTOLA, M.A.F.; PEREIRA, S.A.; CASTRO, J.T.; SANTOS, F.A.O.; FERREIRA, L.C.S. Eventos adversos de vacinas e as consequências da não vacinação: uma análise crítica. Revista de Saúde Pública. v. 52, s/n, p. 1-13, 2018.

BARDIN, L. Análise de conteúdo. Lisboa: Edições 70, 2011.

BRASIL. Ministério da Saúde. Secretaria de Vigilância em Saúde. Programa Nacional de Imunizações $\mathbf{3 0}$ anos. Brasília (DF): Ministério da Saúde, 2003.

COUTO, M.T.; BARBIERI, C.L.A. Cuidar e (não) vacinar no contexto de famílias de alta renda e escolaridade em São Paulo, SP, Brasil. Ciência \& Saúde Coletiva. v. 20, n.1, p. 105-114, 2015.

FONSECA, J. J. S. Metodologia da pesquisa científica. Fortaleza (CE): UEC, 2002.

GIL, A.C. Como Elaborar Projetos de pesquisa. 6 ed. São Paulo (SP): Atlas, 2017.

MARCONI, M.A.; LAKATOS, E.M. Metodologia Científica. São Paulo (SP): Atlas, 2017. 
SCHATZMAYR, H. G. A virologia no Estado do Rio de Janeiro: uma visão global. 2. ed. Rio de Janeiro (RJ): FIOCRUZ, 2012.

VASCONCELLOS-SILVA, P.R.; CASTIEL, L.D.; GRIEP, R.H. A sociedade de risco midiatizada, o movimento antivacinação e o risco do autismo. Ciência \& Saúde coletiva, v. 20, n. 2, p. 607-616, 2015 . 